\title{
Hypothyroidism as a Cause of Precocious Puberty
}

IPEMED

PALETTI, MIKELE T.1, Arbex, Alberto K.1, 2; Rocha, Denise R.1, 2; de Jesus, Ana Luísa C.3; Miranda, Angela Cristina M.1; Sanseverino, Bruna L.1; Cosson, Eliane L. M.1; Takahashi, Fabiana S.1; Caldeira, Flavia Renata S.1; dos Anjos, Hesio José M.1; de Oliveira, Julimar Benedita G. S.1; Faria, Leonardo César S.1; Amicone, Martin A.1; Aguiar, Nícia M. M.1; Júnior, Odon P. B.1; de Souza, Tânia Mara P. A.1; Codonho, Thatiani C. P.1 1. Division of Endocrinology, IPEMED Medical School, São Paulo, Brazil.

2. Federal University of Rio de Janeiro, Rio de Janeiro, Brazil.

3. Graduate of Sergipe Medical School, Federal University of Sergipe.

\section{Introduction}

Hypothyroidism is a rare cause of early puberty in childhood. It reduces the growth rate by decreasing the amplitude of GH pulses. We report the case of a child who developed precocious puberty and reduced speed consequent to hypothyroidism growth. The treatment of thyroid disease with levothyroxine led to regression of pubertal development and resumption of growth.

\begin{tabular}{l|}
\hline Tanner Criteria \\
\hline Weight \\
\hline Height \\
\hline TSH (NR:0,4/4,5) \\
\hline FSH (NR<4 mU/MI) \\
\hline Estradiol (NR<18,0) \\
\hline Bone age \\
\hline
\end{tabular}

March 2011

M2 P1

$11 \mathrm{Kg}$

$80 \mathrm{~cm}$

$7.48 \mathrm{U} / \mathrm{L}$

$4.1 \mathrm{U} / \mathrm{L}$

$15 \mathrm{U} / \mathrm{L}$

18 months -2 years

Weight X Height

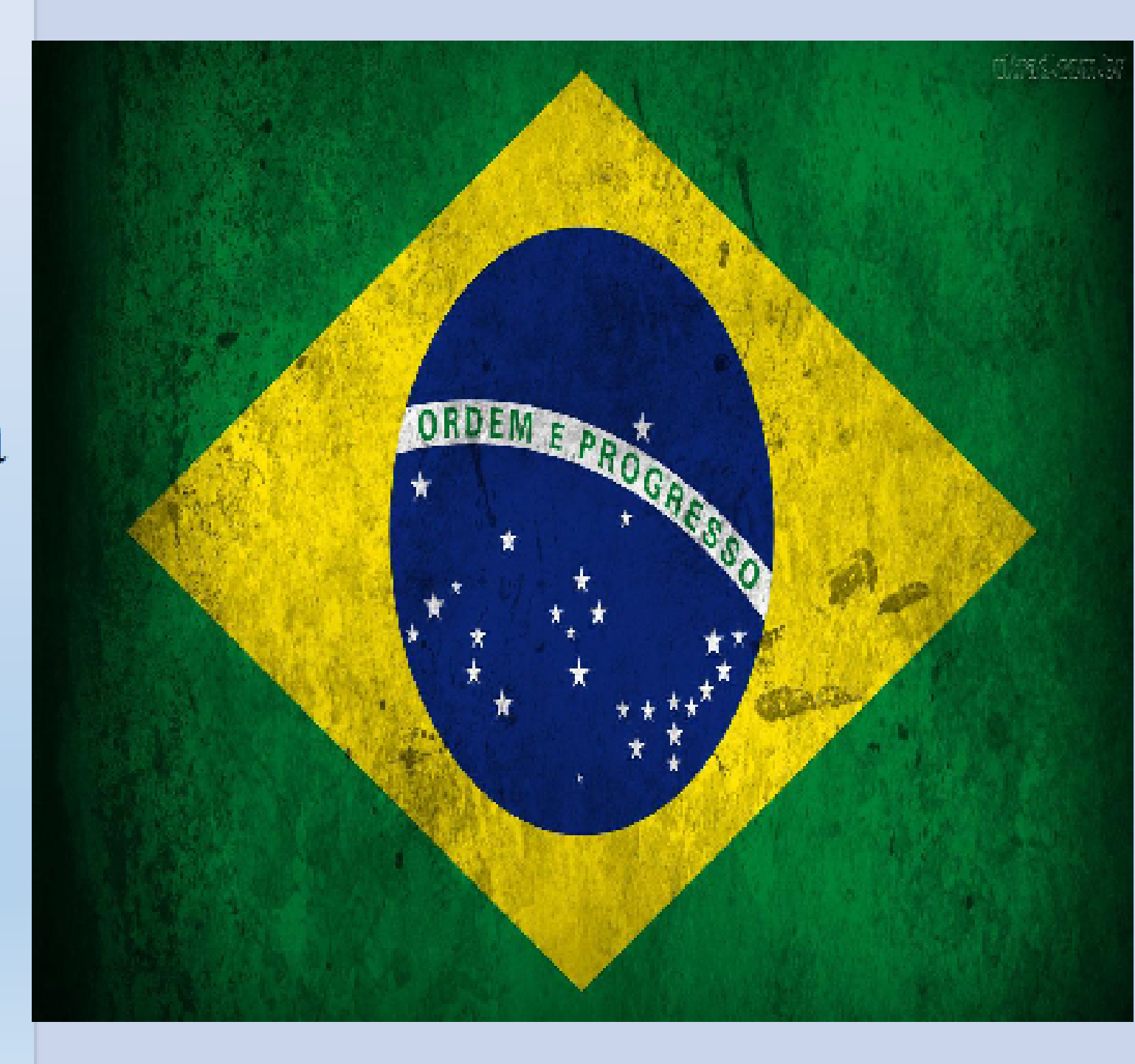

April 2014

M2 P1

$17.6 \mathrm{Kg}$

$105 \mathrm{~cm}$

$7.94 \mathrm{U} / \mathrm{L}$

$3.79 \mathrm{U} / \mathrm{L}$

$33.6 \mathrm{U} / \mathrm{L}$

2 years

120

\section{Methods}

A.J.S., female, 1 year and 5 months of age at first consultation. She came the endocrinology service in March 2011, complaining about bilateral breast enlargement since birth. Her mother reported pregnancy without complications. Cesarean delivery, birth weight and height were $48 \mathrm{~cm}$ and $3.3 \mathrm{~kg}$, respectively. Breast feeding up to 10 months, and she denied the use of medications. Physical examination in 2011 showed Tanner M2 P1, genitals and thyroid gland without changes on physical examination, $11 \mathrm{~kg}$ weight and $80 \mathrm{~cm}$ in height (50-75 percentile).

\section{0}

80

60

40

20

0

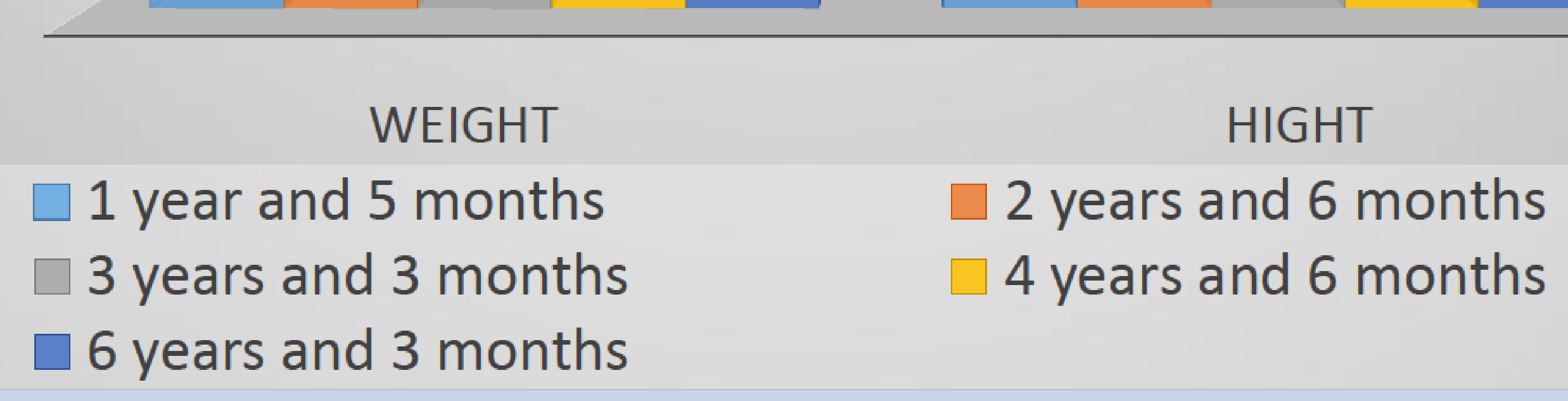

\section{Results}

In 2011, TSH was 7.48U/L, LH: <0.71U/L, FSH: 4.1U/L, Estradiol: 15 U/L. US breast: stromal gland was stimulated. Pelvic US showed no change. Bone age was 18 months to 2 years. The conduct was to prescribe levothyroxine $50 \mathrm{mcg} /$ day. When she became 2 years and 6 months old she had a Tanner M2P2. Weight: $13.5 \mathrm{~kg}$ and height: $91.5 \mathrm{~cm}$. TSH: $1.69 \mathrm{U} / \mathrm{L}$, Free T4: $33.6 \mathrm{U} / \mathrm{L}$. Growth rate of $11.5 \mathrm{~cm} /$ year. She came back in January 2013, with Tanner M2P2, Height: $97.5 \mathrm{~cm}$, Weight: $16.4 \mathrm{Kg}$. On April 2014: Weight: $17.6 \mathrm{~kg}$ and Height: $105 \mathrm{~cm}$, Tanner M2P1, free T4 was 1.18U/L, TSH: 7.94U/L. Estradiol: 33.6, FSH: 3.79U/L. Bone age $=2$ years old. Growth rate 04/2014 to 04/2015: $8.5 \mathrm{~cm} /$ year, the patient was euthyroid. January 2016 she was asymptomatic, in use of levothyroxine $75 \mathrm{mcg}$ / day, Tanner: M2P1, Height: $116 \mathrm{~cm}$, Weight: $23.8 \mathrm{Kg}$ The patient's target height is $162.5 \mathrm{~cm}$.

\section{Discussion}

Precocious puberty may be associated with thyroid hypofunction, and the action of estrogen on the epiphyseal plates might reduce this delay. Patients with high levels of TSH are more likely to develop precocious puberty.

\section{References}

. Cabrera, S.M., DiMeglio, L.A. and Eugster, E.A., 2013. Incidence and characteristics of pseudoprecocious puberty because of severe primary hypothyroidism. The Journal of pediatrics, 162(3), pp.637-639.

2. Anasti, J.N., Flack, M.R., Froehlich, J., Nelson, L.M. and Nisula, B.C., 1995. A potential novel mechanism for precocious puberty in juvenile

hypothyroidism. The Journal of Clinical Endocrinology \& Metabolism, 80(1), pp.276-279.

3. Fuqua, J.S., 2013. Treatment and outcomes of precocious puberty: an update. The Journal of Clinical Endocrinology \& Metabolism, 98(6), pp.2198-2207.

\section{Contact}

albertoarbex@gmail.com 